\title{
First observational study during a solar eclipse event on variations in the horizontal winds simultaneously in the troposphere-stratosphere- mesosphere-lower-thermosphere region over the equatorial station Thumba $\left(8.5^{\circ} \mathrm{N}, 77^{\circ} \mathrm{E}\right)$
}

\author{
Geetha Ramkumar $^{1}$, K. V. Subrahmanyam ${ }^{1}$, K. Kishore Kumar ${ }^{1}$, Siddarth Shankar Das ${ }^{1}$, Debadatta Swain ${ }^{1}$, \\ S. V. Sunilkumar ${ }^{1}$, K. V. S. Namboodiri ${ }^{2}$, K. N. Uma ${ }^{1}$, Veena Suresh Babu ${ }^{1}$, \\ Sherine Rache John ${ }^{1}$, and Asha Babu ${ }^{1}$ \\ ${ }^{1}$ Space Physics Laboratory, Vikram Sarabhai Space Centre, ISRO, Trivandrum-695022, India \\ ${ }^{2}$ Meterological Facility, Vikram Sarabhai Space Centre, ISRO, Trivandrum-695022, India
}

(Received October 7, 2011; Revised December 14, 2012; Accepted December 18, 2012; Online published August 23, 2013)

\begin{abstract}
The longest annular solar eclipse of the millennium occurred on 15 January, 2010, and was visible over the equatorial station Thumba $\left(8.5^{\circ} \mathrm{N}, 77^{\circ} \mathrm{E}\right)$ around noon time. A host of experiments were carried out to study the variations due to the solar eclipse event on various geophysical parameters, from the Earth's surface to ionospheric heights. The present study focuses on the variation in the horizontal winds in the height regions of $0-65 \mathrm{~km}$ and 80-100 km, using GPS-sondes, rocket-sondes and meteor wind radar. The observations were made during, and after, the maximum obscuration on the day of the eclipse, as well as at the same time on a control day. The observations showed a strengthening/weakening of winds along with directional changes both in zonal and meridional winds in the selected height domains. A drastic change from easterly to westerly is observed at 98 $\mathrm{km}$ during, and after, the maximum phase, but, for the meridional wind, the reversal is observed only after the maximum phase. Variations due to the eclipse were also observed around the tropopause and stratopause in both wind components. However, the observed changes in winds around the tropopause and stratopause could not be attributed unambiguously to the eclipse as day-to-day wind variability is not available in these height regions. The significance of the present study lies in reporting the variations in the horizontal wind components from the ground to the 100-km height region (with a gap around $65-80 \mathrm{~km}$ ), and the characteristics of the atmospheric waves generated due to the mid-day annular solar eclipse.
\end{abstract}

Key words: Solar eclipse, gravity waves, troposphere-stratosphere-mesosphere-lower-thermosphere region.

\section{Introduction}

Solar eclipses are rare events and each eclipse is unique with respect to the time of their occurrence, the percentage of the maximum obscuration, and the path of the eclipse. Despite continuous efforts from various researchers, the regular effects of solar eclipses on atmospheric processes are still not well understood and, hence, cannot be generalized. The movement of the eclipsed region at supersonic speed clearly differs from that of regular solar terminators at sunrise and sunset times. Solar eclipse events provide us with rare opportunities to study and understand wave propagation characteristics, their generation mechanisms and the dynamical processes associated with sudden changes in the thermal structure of the atmosphere. Chimonas (1970) was the first to report that a sudden cooling effect could act as a potential source of gravity waves that are likely to propagate upwards, even into the thermosphere, when the source mechanism changes rapidly. Later, Chimonas and Hines $(1970,1971)$ and Fritts and Luo (1993) described the grav-

Copyright (C) The Society of Geomagnetism and Earth, Planetary and Space Sciences (SGEPSS); The Seismological Society of Japan; The Volcanological Society of Japan; The Geodetic Society of Japan; The Japanese Society for Planetary Sciences; TERRAPUB.

doi:10.5047/eps.2012.12.007 ity wave structure induced by the cooling of the ozone layer in response to a solar eclipse, and the associated forcing of the middle atmosphere. Randhawa et al. (1970) reported the effect of a partial solar eclipse, which took place on 24 December, 1973, on the temperature and winds at the equatorial station of Fort Sherman, Panama Canal Zone $\left(9^{\circ} \mathrm{N}\right.$, $\left.79^{\circ} 67^{\prime} \mathrm{W}\right)$. These observations were based on Locki rocket flights that provided wind and temperature measurements in the limited height region of $47-57 \mathrm{~km}$. Cooling by $3-5^{\circ} \mathrm{C}$ in the 50-52-km layer, and a decrease in wind speed close to the maximum obscuration and an increase in wind speed towards the end of the eclipse, were observed during this particular event.

Appu et al. (1982), making use of rocket measurements from the equatorial station Thumba $\left(8.5^{\circ} \mathrm{N}, 77^{\circ} \mathrm{E}\right)$ in connection with the partial solar eclipse of 16 February, 1980, reported a warming of $10^{\circ} \mathrm{C}$ around $30 \mathrm{~km}$, and a cooling of $14^{\circ} \mathrm{C}$ around $58 \mathrm{~km}$. From balloon measurements, these authors also reported a warming of $5^{\circ} \mathrm{C}$ around 13 $\mathrm{km}$ at Thumba, and a systematic cooling in the $3-20-\mathrm{km}$ height region at Hyderabad. Dutta et al. (1999), conducting balloon measurements from Hyderabad during the 24 October, 1995, eclipse, reported a $\sim 10^{\circ} \mathrm{C}$ cooling below the 
tropopause with no significant change in wind components. Zerefos et al. (2007) conducted concurrent measurements in the troposphere, stratosphere, and ionosphere, from three mid-latitude stations, viz., Athens, Kastelorizo and Thessaloniki, to study eclipse-induced thermal fluctuations during the 29 March, 2006, eclipse event, and reported dominant oscillations of a 30-40-minute period in the parameters related to the ozone layer and the ionosphere, and the main mechanism of generating gravity waves was attributed to thermal stratospheric ozone forcing.

The present study focuses on the variation in horizontal winds, the resulting wave motions, and the dynamical processes observed throughout the tropospheric-stratosphericmesospheric-lower-thermospheric regions due to a solar eclipse over the equatorial station Thumba $\left(8.5^{\circ} \mathrm{N}, 77^{\circ} \mathrm{E}\right)$. This particular study is the first of its kind in the sense that the earlier eclipse-related studies of neutral winds were limited to the lower-mesospheric region and the present study reports the variations in wind, due to a solar eclipse, from near ground to the $100-\mathrm{km}$ region, using balloon-borne GPS sondes, rocket- and radar-based measurements. The perturbations in the temperature structure in the troposphericstratospheric region, which was part of the present study conducted over Thumba during the solar eclipse, have already been published (Subrahmanyam et al., 2011); however, a few results from that paper, relevant to the present study, will be discussed later.

\section{Experimental Setup}

The first contact of the annular eclipse at Thumba was at 11:04 IST (= GMT + 5:30 hr), the maximum obscuration of $\sim 92 \%$ was at 13:14 IST and the last contact was at 15:05 IST. This spectacular event provided a rare opportunity to study the dynamical response of the middle atmosphere at noon-time due to an annular eclipse. Measurements of temperature and winds in the middle atmospheric region were made over the equatorial station Thumba $\left(8.5^{\circ} \mathrm{N}, 77^{\circ} \mathrm{E}\right)$, using balloons, rockets and meteor wind radar during, and after, the maximum obscuration of the Sun. High-altitude balloon ascents carrying in-house-developed Pisharoty GPS sondes (Subrahmanyam et al., 2011) were carried out at 08:00, 10:00, 12:30, and 14:30 IST on 14 January (control day) and 15 January (annular eclipse), 2010, to study the variations in temperature and horizontal winds during, and after, the eclipse in the tropospheric-stratospheric (0$30 \mathrm{~km}$ ) height region. The accuracies of the Pisharoty GPS sonde wind measurements are $1-2 \mathrm{~m} \mathrm{~s}^{-1}$ in wind speed and $5^{\circ}$ in wind direction for wind speeds above $25 \mathrm{~m} \mathrm{~s}^{-1}$ and $10^{\circ}$ for lower wind speeds.

RH-200 rockets carrying a chaff payload were launched at 13:07 and 15:00 IST on the eclipse day, and the control day, to measure the horizontal winds in the stratosphericmesospheric $(30-65 \mathrm{~km})$ region. $\mathrm{RH}-200$ is a two-stage rocket, which uses chaff as a payload to measure the winds in the $20-65-\mathrm{km}$ altitude region with a height resolution of $1 \mathrm{~km}$ (Devarajan et al., 1984). Chaff consists of a large number of very thin strips of metal (usually copper or aluminum) or metalized nylon, cut to half the wavelength size of the radio wave from the tracking radar. Chaff, with its very low ballistic coefficient, is well suited as a wind tracer.
The chaff released at the apogee point of the rocket trajectory is tracked by the ground-based radar to measure the wind velocity in the mesosphere and stratosphere as it descends with time. The chaff gradually spreads in space after its release and is a diffusive radar target. The radar automatically tracks the strongest portion of the diffused echo, and, hence, the position coordinates measured by the radar correspond to the densest part of the diffused chaff cloud. The wind velocity is calculated from the radar measured position coordinates of the chaff $(R, \theta, \varphi)$ as a function of time, where $R, \theta$, and $\varphi$ are the range, elevation and azimuth angles respectively. Standard errors involved in the wind measurements are $2.7 \mathrm{~m} \mathrm{~s}^{-1}$ in $20-30-\mathrm{km}$ altitudes, $1.9 \mathrm{~m} \mathrm{~s}^{-1}$ in the $31-50-\mathrm{km}$ and $3.8 \mathrm{~m} \mathrm{~s}^{-1}$ in the $50-65-\mathrm{km}$ altitude regions (Devarajan et al., 1984).

In addition to the above two techniques, round the clock meteor radar observations at Thumba provided high resolution (15 min) zonal and meridional winds in the 82-98$\mathrm{km}$ region and the daily mean mesopause temperature. The winds derived from the Thumba meteor radar are well comparable with MF radar (Kumar et al., 2007) and TIDI observations (John et al., 2011), and the meteor-radar-derived mesopause temperature is well comparable with SABER and dayglow photometer (Das et al., 2012). For the present study, we have used the wind measurements on the control and eclipse day. A general description of the meteor wind radar can be found in Hocking et al. (2001), and the Thumba meteor radar description and initial results can be found in Deepa et al. (2006) and Kumar et al. (2007). In the case of meteor radar, the radial velocity can be measured with an accuracy of $5 \%$ or better.

\section{Observational Results}

The zonal and meridional wind measurements on 14 and 15 January, 2010, using balloon (12:30-13:30 IST), rocket (13:07-13:30 IST), and meteor wind radar (12:30-13:30 IST), observations around the maximum obscuration of the Sun in the height regions of 0-65 and 82-98 km are analysed to look for the perturbations in wind components and the resulting dynamical processes. For balloon- and rocketbased measurements, the 14 January, 2010, observations were taken as a reference. However, as the meteor radar observations were available round the clock, the reference profile is based on the data collected during the entire month (January 2010). There is a data gap between $65-82 \mathrm{~km}$, which is due to observational limitations ( $\mathrm{RH}-200$ provides wind information up to $65 \mathrm{~km}$ and meteor radar provides data from $82 \mathrm{~km}$ onwards).

In order to quantify the eclipse-induced perturbations in the zonal and meridional winds in the middle atmospheric region, the height profiles of these wind components measured during the maximum obscuration time are compared with that at the same time on the control day. Figures 1(a) and 1(b) show the height profiles of the zonal and meridional winds observed from balloon and rocket flights on 14 and 15 January, 2010, during 12:30-13:30 IST. From Fig. 1(a), it is evident that there is no drastic change in the zonal winds in the entire height region of $0-65 \mathrm{~km}$ during the maximum obscuration phase. However, by carefully examining the profiles shown in Fig. 1(a), a strengthening of 

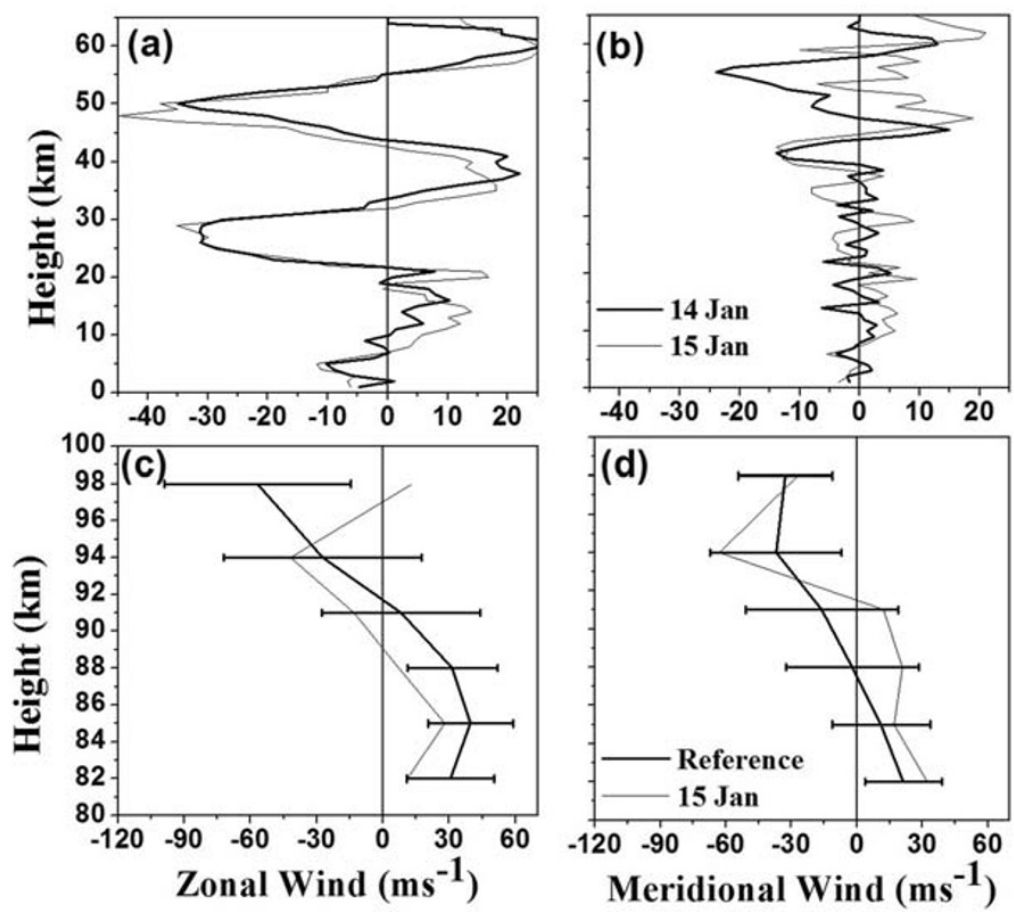

Fig. 1. Height profiles of (a) zonal, and (b) meridional, winds in the 0-65-km height region measured using balloon and rocket ascents during 12:30-13:30 IST (the maximum obscuration). Figure 1(c) and (d) are same as (a) and (b) but for meteor radar measured winds in the MLT region. The horizontal bars in (c) and (d) represent the Standard deviation.

easterlies in the 45-50-km region can be noted along with a strengthening of westerlies in the $8-15-\mathrm{km}$ region in the troposphere. The height profiles of the meridional wind depicted in Fig. 1(b) show a wind reversal from northerlies to southerlies in the height region $45-55 \mathrm{~km}$ during the maximum obscuration on the eclipse day as compared with the control day. Apart from this, the southerlies become stronger in the $10-15-\mathrm{km}$ region. Except at these regions (near to the tropopause and stratopause), there is not much drastic change in the meridional wind during the maximum phase of the eclipse. Figures 1(c) and 1(d) show the zonal and meridional winds in the MLT region during the maximum phase of the eclipse, measured using meteor wind radar. The standard error in the zonal and meridional winds measured from meteor radar is found to vary from 3-5 $\mathrm{m} \mathrm{s}^{-1}$. As mentioned earlier, the reference profiles of zonal and meridional winds in the MLT region are constructed using the observations during the entire month of January 2010. From this figure, it is evident that the zonal wind shows a directional change from easterlies to westerlies which are distinct from the day-to-day variability. The meridional winds do show a variability, but this is within the standard deviations. Thus, during the maximum phase of the eclipse there are large directional changes in the meridional wind around the $45-55-\mathrm{km}$ region, and in zonal winds around the $98-\mathrm{km}$ height region.

Further, to quantify the observed wind variations in the troposphere, stratosphere, and mesosphere, during the eclipse, the difference between the eclipse and the control day wind profiles are obtained. As we are having the wind measurements at the same time of the day on both the control and eclipse days, it is helpful to minimize the contami- nations due to the diurnal tide. Figures 2(a) and 2(b) show the height profiles of the fluctuations in the zonal and meridional winds, respectively, during the maximum phase of the eclipse. The zonal wind fluctuation depicted in Fig. 2(a) shows noticeable changes of the order of $25 \mathrm{~m} \mathrm{~s}^{-1}$ around the $48-\mathrm{km}$, and $\sim 15 \mathrm{~m} \mathrm{~s}^{-1}$ around the $18-\mathrm{km}$, height region, apart from a change of more than $10 \mathrm{~m} \mathrm{~s}^{-1}$ around the 15-, $35-$ and $52-\mathrm{km}$, regions. The day-to-day variability in zonal and meridional wind measured in the $0-65-\mathrm{km}$ region was found to be less than $10 \mathrm{~m} \mathrm{~s}^{-1}$ from rocket (with available RH-200 data on two successive days in the month of January 2005) and balloon observations. The meridional wind fluctuation presented in Fig. 2(b) exhibits large variations of more than $30 \mathrm{~m} \mathrm{~s}^{-1}$ around the $55-\mathrm{km}$ height region and $20 \mathrm{~m} \mathrm{~s}^{-1}$ around the $60-\mathrm{km}$ height region. Both the zonal and meridional winds exhibit a large wind shear in the 45$65-\mathrm{km}$ height region which can act as a source for the generation of waves. However, the observed variability in both zonal and meridional winds cannot be entirely attributed to eclipse-induced effects as there will be day-to-day variability. Unfortunately, we don't have enough observations to quantify the day-to-day variability of winds in the region of interest. However, using earlier rocket observations on two consecutive days in the month of January 2005, we observed that the day-to-day variability is within $10 \mathrm{~m} \mathrm{~s}^{-1}$ (figure not shown) and the perturbations in the present case are much above this. However, it is to be remembered that this is not the deviations from the mean profiles. Since the perturbations above $20 \mathrm{~m} / \mathrm{s}$ should be important in this case, and thus only the variations at around $55 \mathrm{~km}$ (Fig. 2(b)) could be the unambiguous response of the eclipse.

In an attempt to study the delayed effect of the annular 


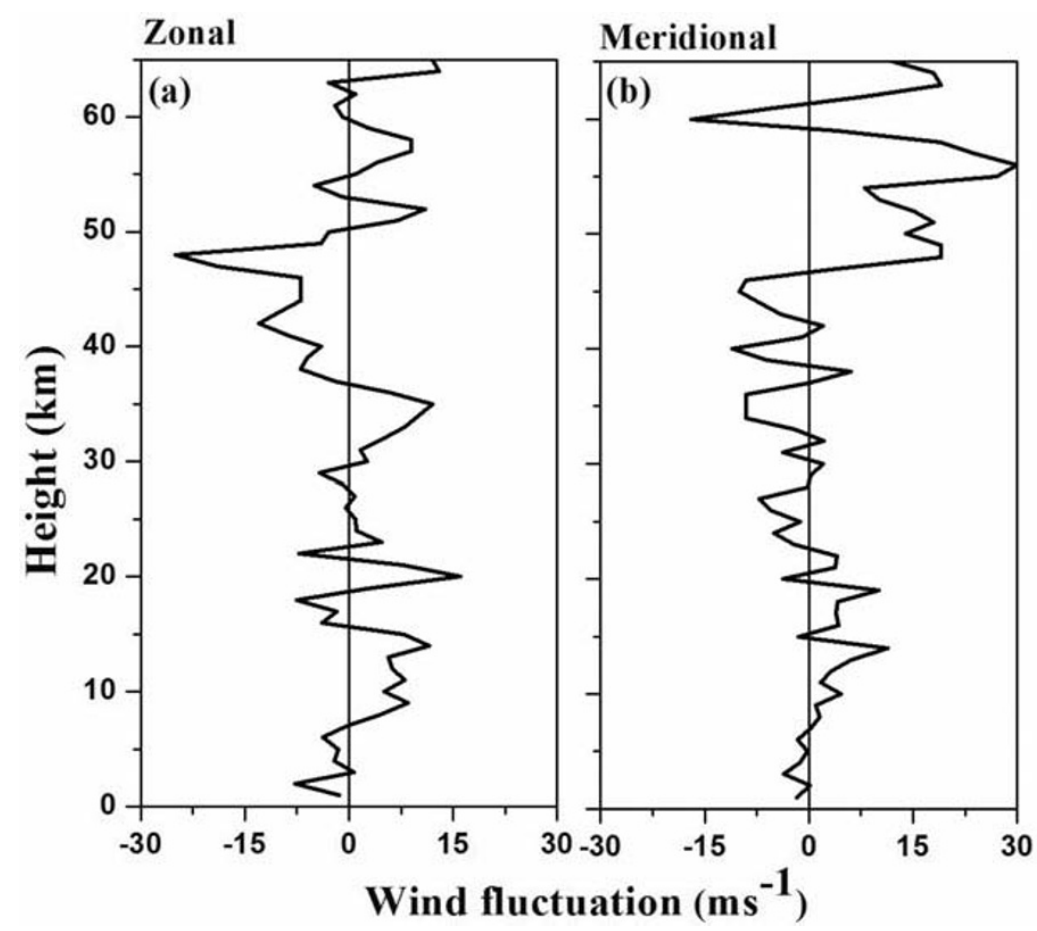

Fig. 2. Height profiles of (a) zonal, and (b) meridional, wind fluctuations measured in the 0-65-km region during the maximum obscuration.

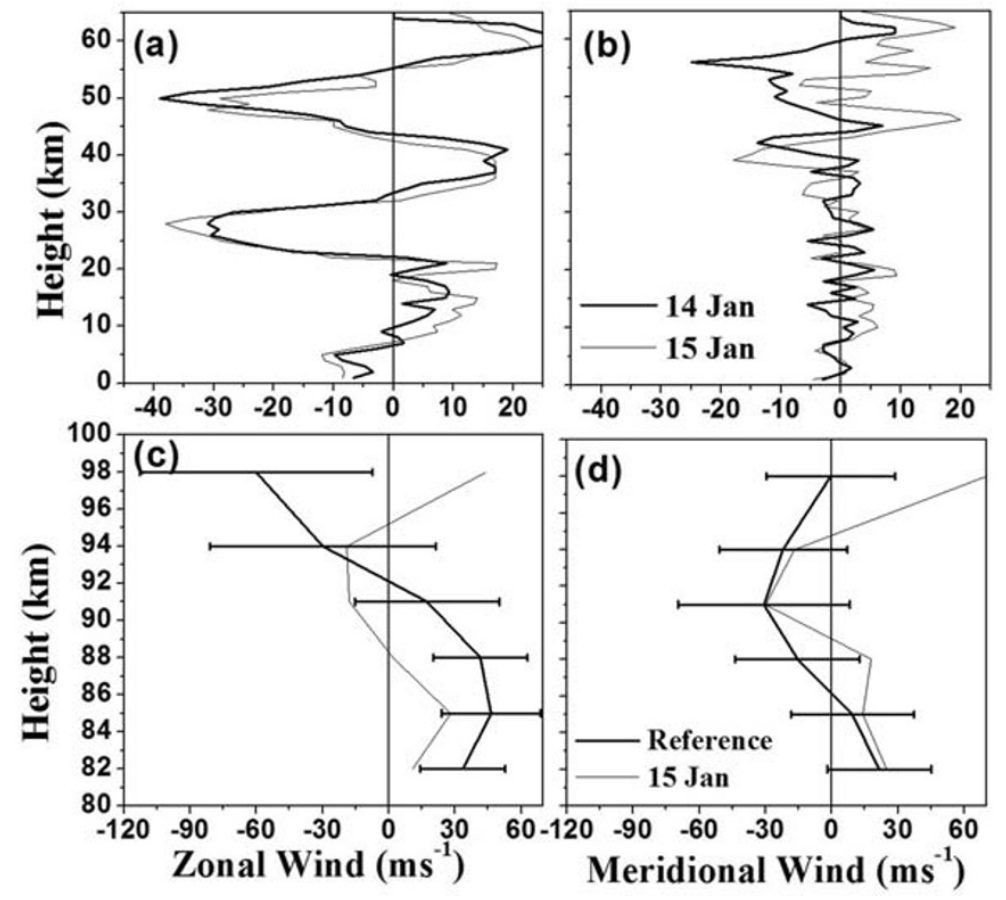

Fig. 3. Same as Fig. 1, but observed during 14:30-15:30 IST ( 2 hrs after the maximum obscuration).

solar eclipse on winds, the same set of observations were carried out as mentioned earlier during 14:30-15:30 IST on the control and eclipse days. Figures 3(a) and (b) show the height profiles of zonal and meridional winds during 14:30-15:30 IST on both the control and eclipse days in the $0-65-\mathrm{km}$ height region. From these figures it can be noted that there is a substantial decrease in easterly winds in the 45-50-km region as compared to the control day, and, at the same time, there is an increase in easterly winds in the $25-30-\mathrm{km}$ height region. The height profiles of meridional winds (Fig. 3(b)) show similar variations as during the maximum phase of the eclipse (Fig. 1(b)) except for an increase in northerly winds around the $35-40-\mathrm{km}$ region towards the end of eclipse. Figures 3(c) and 3(d) show the zonal and meridional winds during 14:30-15:30 IST in the MLT region, observed from the meteor radar. The zonal wind reversal at $98 \mathrm{~km}$ further intensified two hours after the maximum obscuration. The westerlies in the 82-88- 


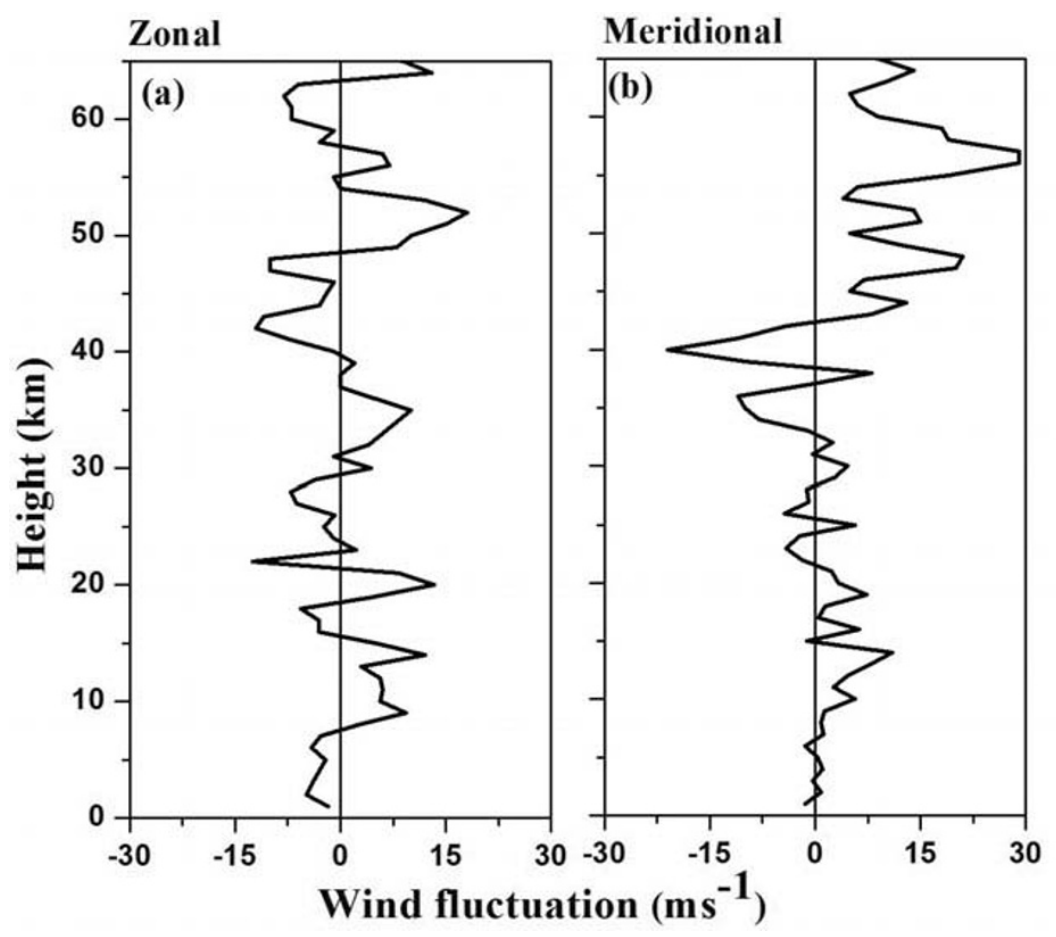

Fig. 4. Same as Fig. 2, but observed during 14:30-15:30 IST (2 hrs after the maximum obscuration).

$\mathrm{km}$ region appear to be weakened as can be seen clearly from Fig. 3(c). The meridional winds in the MLT region show remarkable changes after the maximum phase of the eclipse compared with that during the maximum phase of the eclipse, as shown in Fig. 1(d). There are directional changes from northerlies to southerlies at $98 \mathrm{~km}$. Thus, there are significant changes in the horizontal wind components on the eclipse day compared with those on control day and, more importantly, the variations in the wind components during and after the maximum phase of the eclipse are distinctly different.

Further, to quantify the delayed effect of the eclipse on the zonal and meridional wind fluctuations, these fluctuation profiles during 14:30-15:30 IST on the eclipse and control days are compared, as shown in Fig. 4(a) and (b), respectively. It is evident that the wind variations observed during the maximum phase of the eclipse are still persisting at the same height regions. However, the magnitude of wind variations observed in the $45-50-\mathrm{km}$ region is found to be reduced during 14:30-15:30 IST (Fig. 4(a)) compared to observations during 12:30-13:30 IST (Fig. 2(a)). At the same time, zonal wind perturbations picked up in the 50$65-\mathrm{km}$ height region with large wind shears. The meridional wind fluctuations after 2 hours of the maximum phase of the eclipse depicted in Fig. 4(b) shows an increased southward amplitude of $25 \mathrm{~m} \mathrm{~s}^{-1}$ around the $40-\mathrm{km}$ height region and changes northward in the $40-65-\mathrm{km}$ region with shortscale fluctuations. The height profiles depicted in Figs. 2 and 4 exhibit fluctuations with shorter vertical wavelengths, which could be due to the gravity waves generated from the strong wind shears and sudden changes in temperature due to the eclipse effect. However, it is to be remembered that we do not have the actual day-to-day wind variability during the month of January 2010 in the altitude region 0-60 $\mathrm{km}$ and, thus, results are qualitative in this height region.

In order to characterize and quantify the short-scale fluctuations, and to get a better picture of eclipse-induced wave characteristics, the height profiles of the wind fluctuations were subjected to Fourier analysis, after subtracting a second-order polynomial fit from all the profiles. The choice of the order of the polynomial is subjective and the possible effects of the order of the polynomial on the vertical wavelength spectrum can be found in Babu et al. (2008). The wavelength spectra for the troposphere and stratosphere are shown in Figs. 5(a) and (b), respectively. Upper panels are for the zonal wind and lower panels are for the meridional winds. The left panels are during the maximum obscuration, and the right panels are after the maximum obscuration. Only those spectral peaks, which are above the 95\% significance level are considered. In general, a substantial increase in the amplitude of shorter $(2-8 \mathrm{~km})$ vertical wavelengths in the zonal and meridional wind components in the troposphere and stratosphere during the maximum obscuration, and even after 2 hours of the maximum obscuration, is found on the eclipse day compared to that on control day. In the troposphere, the zonal wind component shows a predominant amplitude of $6 \mathrm{~m} \mathrm{~s}^{-1}$ on the eclipse day and $4 \mathrm{~m} \mathrm{~s}^{-1}$ on the control day, which correspond to a $\sim 6 \mathrm{~km}$ vertical wavelength. This feature is observed during, and after $2 \mathrm{hrs}$ from, the time of maximum obscuration. Similarly, a 6-km vertical wavelength in the meridional component shows an enhanced amplitude of $\sim 2 \mathrm{~m} \mathrm{~s}^{-1}$ during the eclipse phase compared with $\sim 1$ $\mathrm{m} \mathrm{s}^{-1}$ on the control day, whereas, after the maximum obscuration, the amplitude corresponding to a $6-\mathrm{km}$ vertical wavelength becomes $2.5 \mathrm{~m} \mathrm{~s}^{-1}$ compared with $1.3 \mathrm{~m} \mathrm{~s}^{-1}$ on the control day. The increase in amplitude at stratospheric heights is found to be comparatively less. The amplitude 

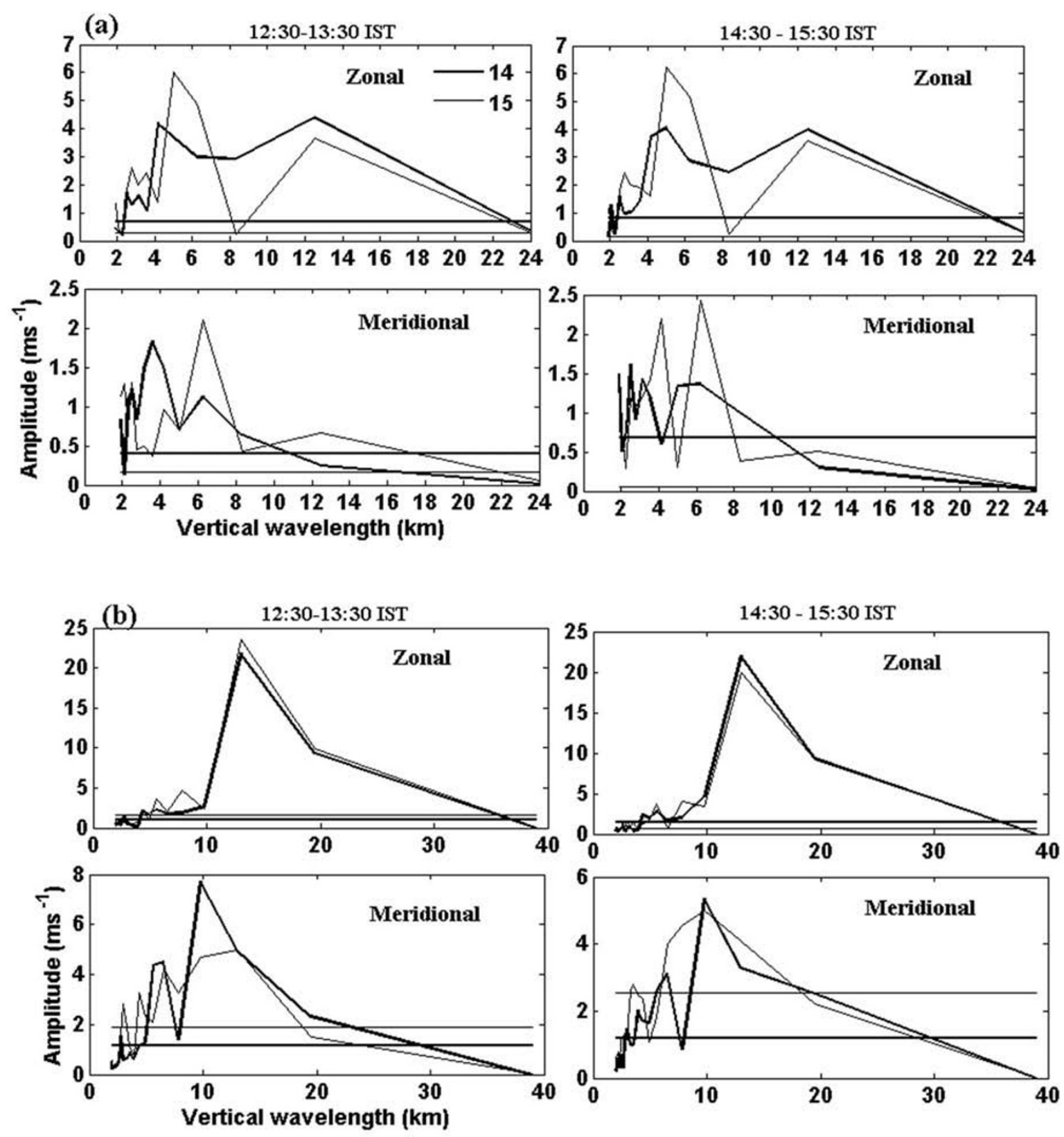

Fig. 5. The vertical wavelength spectra of zonal winds (upper panel), and meridional winds (lower panels), observed during 12:30-13:30 hrs (left panels) and 14:30-15:30 hrs (right panels) in the (a) troposphere, and (b) stratosphere, for the control day (blue) and the eclipse day (red). The horizontal lines in all the plots indicate the $95 \%$ significance level.

of larger (10-16 km) vertical wavelengths remains almost the same during, and after, the maximum obscuration in the troposphere and stratospheric region and this can be attributed to short-period planetary waves not associated with the eclipse. Thus, the enhanced amplitudes of short vertical wavelengths of $(2-8 \mathrm{~km})$ throughout the troposphere and stratosphere can be attributed to gravity waves triggered by the eclipse-induced wind shear and thermal perturbations. However, this is only a possibility as we don't have the dayto-day variability of winds in these height regions.

Since high resolution wind measurements with an interval of a few minutes is not possible with balloon and rocket flights, the time period of the perturbations cannot be determined in the $0-65-\mathrm{km}$ height region. However, the potential of meteor radar to make continuous measurements of winds with a high temporal resolution $(\sim 15 \mathrm{~min})$ could be used to extract this information on the periodicity of eclipse-induced perturbations in the height region of 80 $100 \mathrm{~km}$. Figures 6(a) and (b) show the height time section of zonal winds on the eclipse day and the mean of all other days during January 2010, respectively. The wind reversal from westward to eastward at 94 and $98 \mathrm{~km}$ during the course of the eclipse (13:00-17:00 IST) can be readily seen from Fig. 6(a). One more interesting observation from Fig. 6(a) are the strong westward winds during 16:0022:00 IST above $90 \mathrm{~km}$. Figures 6(c) and (d) are the same as Figs. 6(a) and (b), but for meridional winds, which show a wind reversal above the $90-\mathrm{km}$ height region during the course of the eclipse. The meridional wind also shows wind reversal with respect to the mean diurnal variation shown in 


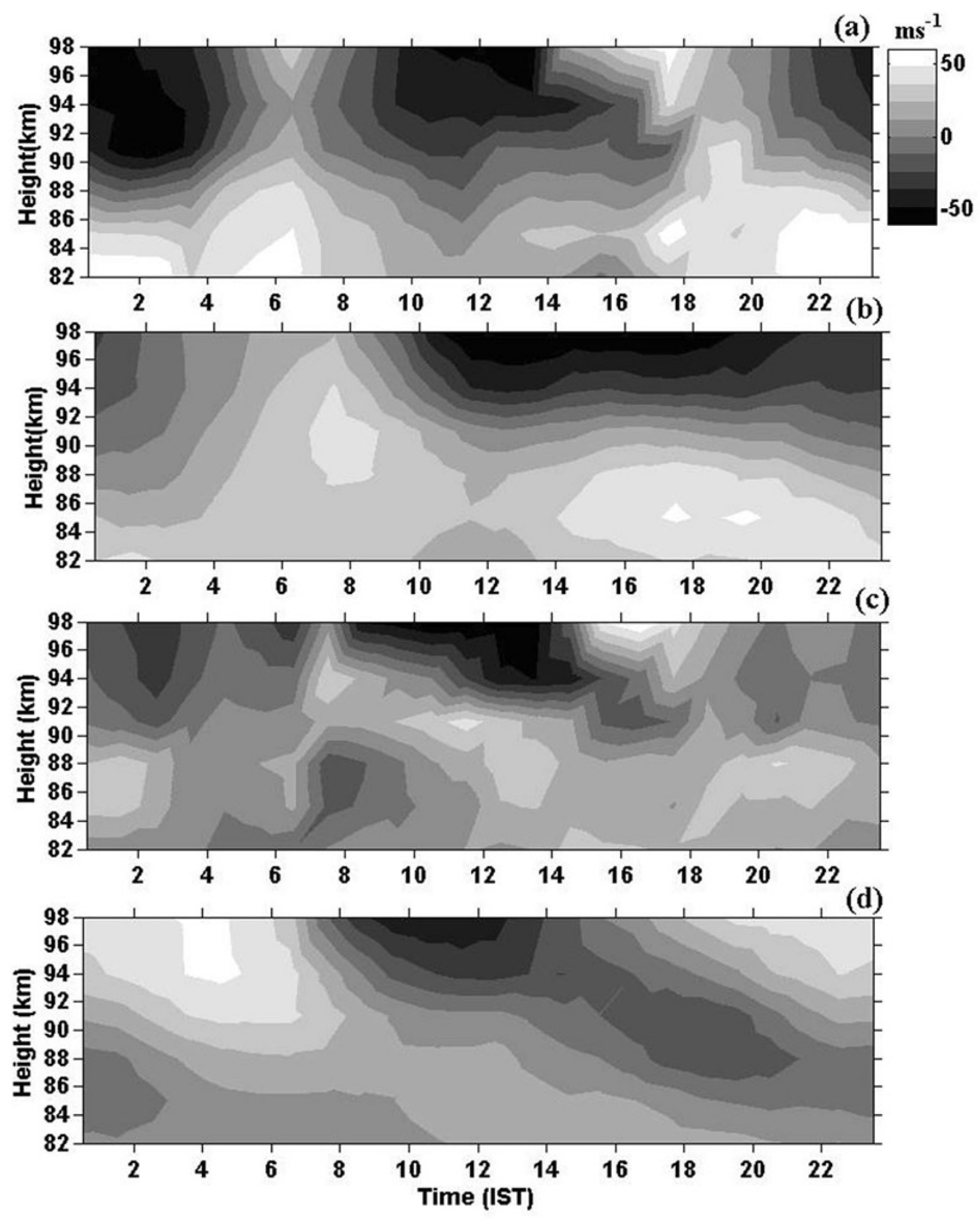

Fig. 6. (a) Time-height section of zonal winds on the eclipse day, and (b) mean time-height section of the zonal wind during January 2010. (c) and (d) are the same as (a) and (b) but for meridional wind.

Fig. 6(d) below $90 \mathrm{~km}$ during 12:00-20:00 IST. The zonal and meridional wind components in the MLT region clearly show short-period perturbations during, as well as after, the maximum phase of the eclipse, compared with the reference profile (mean of January 2010, except the eclipse day observations).

In order to extract the characteristics of gravity waves generated due to the annular eclipse, the time series of mean removed wind perturbations are subjected to wavelet analysis, which provides the time evolution of spectral components. Figure 7 shows the wavelet spectra of zonal and meridional winds at $98 \mathrm{~km}$ on the control day (a, b), and on the eclipse day (c, d). The wavelet spectra in zonal and meridional winds show the presence of 30-min-, and 80100-min-period, waves with an enhanced amplitude of $30 \mathrm{~m}$ $\mathrm{s}^{-1}$ during the maximum phase of obscuration, i.e. 12:00-
15:00 IST on the eclipse day (Figs. 7 (c), (d)) compared to that on the control day. However, such a periodicity is also present in the zonal component on the control day, but the amplitude is much less $\sim 10 \mathrm{~m} \mathrm{~s}^{-1}$. This shows that the enhanced amplitude of 30-min and 80-100-min periodicity observed in both the wind components on 15 January, 2010, could be due to the eclipse induced effect.

Figure 8 shows the height profiles of the amplitude and phase of a prominently present 80 -min-period gravity wave in the zonal and meridional components. The dotted lines in the height profiles of the phase indicate the propagation, which is fitted by a least-square method. It is clear from the figures that the wave propagates upward from the region below $80 \mathrm{~km}$ and downwards from the region above 98 $\mathrm{km}$. This is indicative of the fact that there are two source regions: one above the $98-\mathrm{km}$, and the other below the 

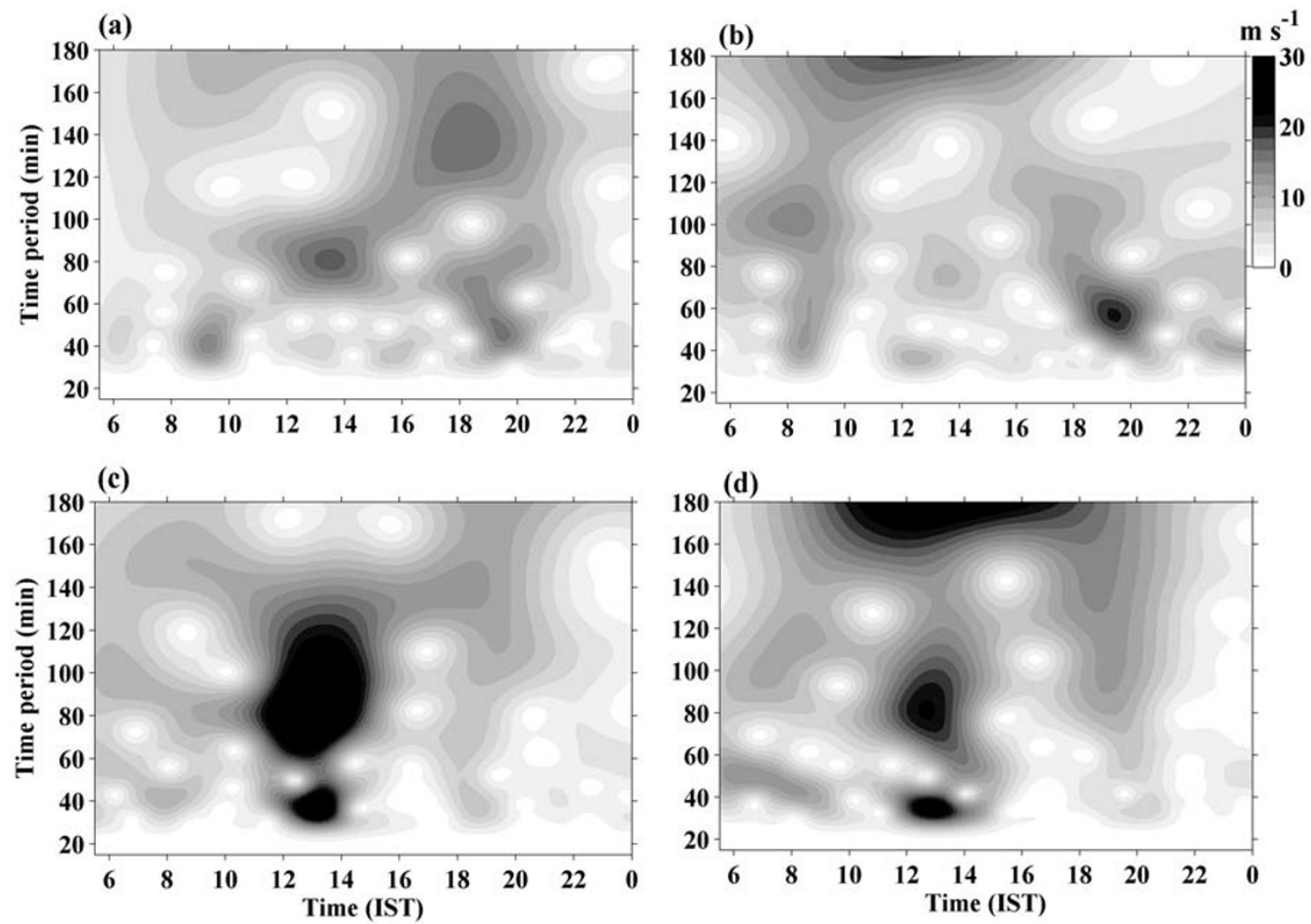

Fig. 7. Wavelet spectra of (a) zonal, and (b) meridional, winds at $98 \mathrm{~km}$ on the eclipse day. (c) and(d) are the same as (a) and (b) but for the control day.

(a)
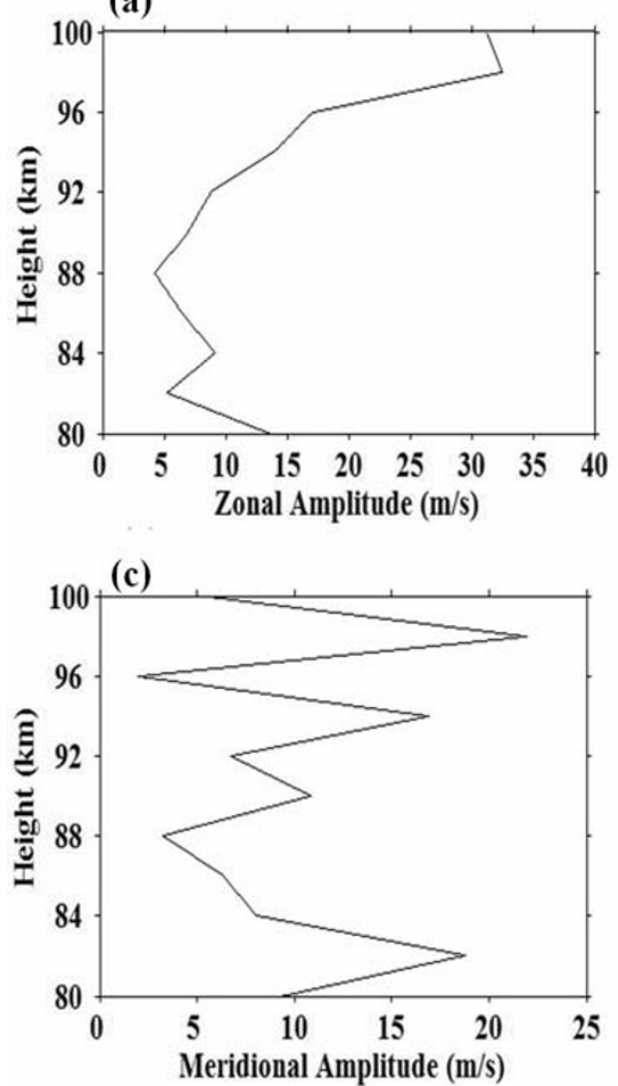

(b)
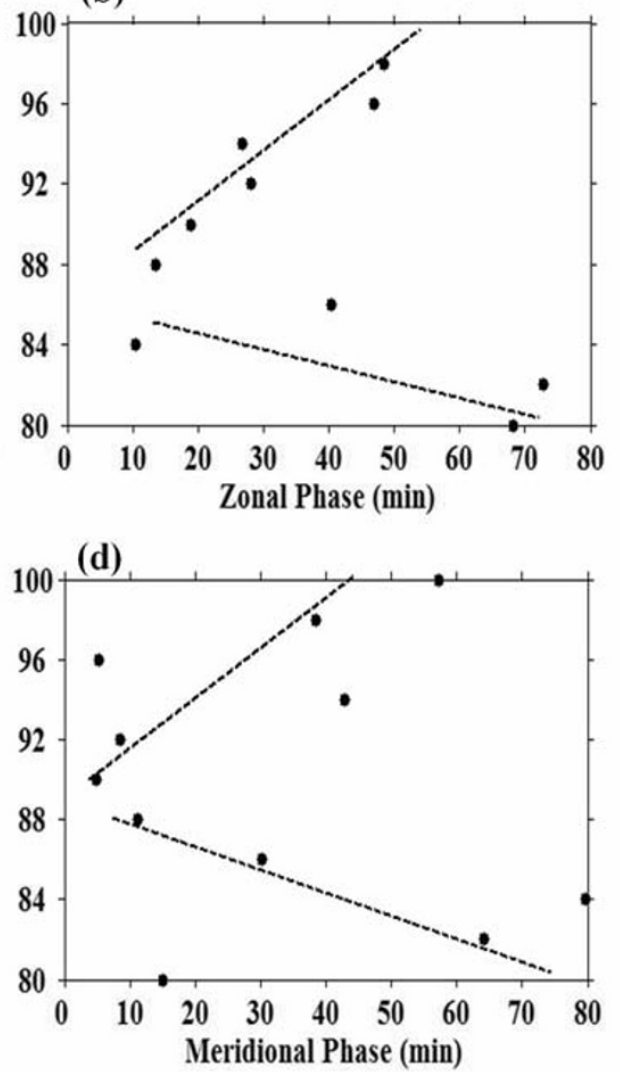

Fig. 8. Height profiles of (a) amplitude, and (b) phase, of the dominant 80-minute-period gravity wave observed in zonal winds. (c) and (d) are the same as (a) and (b) but for meridional winds. The dotted inclined line indicates the downward and upward propagation of the wave. 
80-km, height region. The following section presents a discussion on the possible reasons for the observed features of the wind components on the eclipse day.

\section{Discussion and Concluding Remarks}

The Moon's shadow moves through the Earth's atmosphere at supersonic speed during an eclipse event and, thus, screens the solar radiation, eventually blocking the direct solar heating of ambient air on, and above, the ground. This, in turn, reduces upward long-wave heating of the ambient air above the ground, generating an effective cooling spot. During the solar eclipse, the absorption of ultraviolet radiation by ozone that heats the middle atmosphere is cut off in the shadow region. The cooling of the upper layers produces subsidence/contraction in the lower atmospheric regions, which induces a downward movement. The downward motion adiabatically heats the lower atmosphere resulting in a warming of that region. The sudden change in temperature and the associated wind shears can act as a source for the generation of gravity waves. Thus, one should expect changes in the thermal structure, as well as the wind system, due to the eclipse effect. Recently, Subrahmanyam et al. (2011) reported a decrease of temperature of the order of $2-4^{\circ} \mathrm{C}$ in the lower and upper troposphere, and $6-8^{\circ} \mathrm{C}$ in the lower stratosphere, during the annular eclipse of 15 January, 2010, over the same location of Thumba. Also, it is seen that towards the end of the eclipse, the temperature slowly returned to its normal value, except in the lower stratosphere, where the difference in the temperature fluctuation was beyond the diurnal temperature fluctuations. Using balloon flights carrying ozone sondes from the same location, Manchanda (personal communication) observed a cooling of the order of $5^{\circ} \mathrm{C}$ in the $36-40-\mathrm{km}$ height region along with a decrease in the stratospheric ozone peak value by $\sim 8 \%$. From high resolution mesopause $(\sim 90 \mathrm{~km})$ temperature measurements over Thumba using a Multi Wavelength Dayglow Photometer, Sumod et al. (2011) reported enhancements of the mesopause temperature of the order of $35 \mathrm{~K}$, and the generation of gravity waves with periods from 30 minutes to 2 hours.

The change in temperature can also cause changes in pressure over the totality footprint. The sudden change in the stratospheric pressure during the solar eclipse may also be responsible for the generation of gravity waves in the stratosphere (Zerefos et al., 2007). Thus, these variations throughout the middle atmosphere, in turn, can result in variations in neutral winds and wind shears which, in turn, give rise to short-scale fluctuations. The horizontal wind measurements throughout the middle atmospheric region over the equatorial station Thumba during the annular eclipse event of 15 January, 2010, are used to study the dynamical processes during the eclipse which are associated with wave motions produced in the region of local temperature changes of the atmosphere as the Moon's shadow advances at supersonic speeds. Eclipse-induced perturbations could be found in the vertical profiles of the zonal and meridional winds throughout the middle atmospheric region over Thumba. The MLT region zonal wind showed a reversal at $98 \mathrm{~km}$ during the maximum phase of the eclipse and the reversal is further strengthened after the maximum phase. The meridional wind in the MLT region showed noticeable changes only after the maximum phase of the eclipse. These observed changes in the wind system are attributed to eclipse-induced cooling and subsequent changes in the pressure in the middle atmosphere over Thumba. Winkler et al. (2001) have argued that factors such as the cooling rate, the inversion strength and height, and the pressure gradient could induce strong wind shear and turbulent mixing, thus substantiating the wind variations associated with the eclipse.

The Fourier analysis of height profiles of wind fluctuations revealed the presence of 2-8-km-vertical wavelengths in the wind components during, and after, the maximum phase of the eclipse in the troposphere and stratosphere. Gravity waves, generated away from this location earlier, along the path of the eclipse can also reach this location, thus manifesting in the form of multiple wavelengths. The spectral analysis of the time series of wind data in the MLT region could reveal the presence of 30-minute- and 80-100minute-period gravity waves.

Looking at the source region of these waves and their propagation characteristics, it is understood that there can be multiple sources separated in height throughout the middle atmospheric region. We have observed the downward propagation of a wave from $98 \mathrm{~km}$ to $88 \mathrm{~km}$, as shown in Fig. 8, and an upward propagating wave from the region below 80 to $88 \mathrm{~km}$. These observations indicate the possibility of multiple source regions from where upward and downward propagating waves originate. Hodograph analysis of horizontal winds in the $50-100-\mathrm{km}$ region (not presented) also showed a clockwise and anti-clockwise rotation of the wind vector around the $60-\mathrm{km}$, and around the 98-km, height region, indicating the possible location of the source regions that generate gravity waves. The elliptical path of the wind vector rotation in all the cases conform with the characteristics of gravity waves. These source regions are believed to be at the regions where the maximum perturbation in temperature is observed. Thus, the present study, for the first time, has examined the horizontal winds in throughout the $0-100-\mathrm{km}$ region (with a gap at $65-80$ $\mathrm{km}$ ) during a solar eclipse and has brought out the salient features of eclipse-induced wind perturbations and the associated dynamics. However, the observed wind perturbations in the troposphere and stratosphere could not be attributed entirely to the eclipse, as the day-to-day variability was not available in these height regions.

Acknowledgments. The authors acknowledge the support provided by scientists and engineers of the ATV Project, Thumba Rocket launching station and Meteorological Facility, Vikram Sarabhai Space Centre, Trivandrum. The support and encouragement provided by Prof. R. Sridharan, Former Director, Space Physics Laboratory (SPL) and Dr. K. Krishnamoorthy, Director, SPL are greatly appreciated. The authors, Uma, Veena, Sherin and Asha wish to thank the Indian Space Research Organisation (ISRO) for their research fellowship during the study presented here.

\section{References}

Appu, K. S., B. V. Krishanmoorthy, V. Narayanan, C. A. Reddy, and K. Sengupta, Thermal structure of the atmosphere-surface to mesosphere- 
during the solar eclipse of 16 February 1980, Proc. Indian Natn., Sci. Acad, 48A, 506, 1982.

Babu, A. N., K. K. Kumar, G. K. Kumar, M. V. Ratnam, S. V. B. Rao, and D. N. Rao, Long-term MST radar observations of vertical wavenumber spectra of gravity waves in the tropical troposphere over Gadanki (13.50N, 79.20 359 E): Comparison with model spectra, Ann. Geophys., 26, 1671-1680, 2008.

Chimonas, G., Internal gravity-wave motions induced in the earth's atmosphere by a solar eclipse, J. Geophys. Res., 75, 5545-5551, 1970.

Chimonas, G. and C. O. Hines, Atmospheric gravity waves induced by a solar eclipse, J. Geophys. Res., 75, 875, 1970.

Chimonas, G. and C. O. Hines, Atmospheric gravity waves induced by a solar eclipse, J. Geophys. Res., 76, 7003-7005, 1971.

Das, S. S., K. K. Kumar, S. K. Das, C. Vineeth, T. K. Kumar, and G. Ramkumar, Variability of mesopause temperature derived from two independent meteor radar methods and its comparison with SABER and EOS-MLS and a co-located multi-wavelength day-glow photometer, over the equatorial station Thumba $\left(8.5^{\circ} \mathrm{N}, 76.5^{\circ} \mathrm{E}\right)$, Int. J. Rem. Sen., 33, 4634-4647, 2012.

Deepa, V., G. Ramkumar, T. M. Antonita, K. K. Kumar, and M. N. Sasi, Vertical propagation characteristics and seasonal variability of tidal wind oscillations in the MLT region over Trivandrum $\left(8.5^{\circ} \mathrm{N}, 77^{\circ} \mathrm{E}\right)$ : first results from SKiYMET meteor radar, Ann. Geophys., 24, 28772889, 2006.

Devarajan, M., P. R. Parameswaran, C. A. Reddy, and C. R. Reddy, Accuracy of stratospheric wind measurements using chaff releases from RH-200 rockets, Indian J. Radio Space Phys., 13, 48-55, 1984.

Dutta, G., M. N. Joshi, N. Pandarinath, B. Bapiraju, S. Srinivasan, J. V. Subba Rao, and H. A. Basha, Wind and temperature over Hyderabad during the eclipse of 24 Oct.1995, Indian J. Radio Space Phys., 28, 1114, 1999.

Fritts, D. C. and Z. Luo, Gravity wave 374 forcing in the middle atmosphere due to reduced ozone heating during a solar eclipse, J. Geophys. Res., 98, 3011-3021, 1993.

Hocking, W. K., B. Fuller, and B. Vandepeer, Real-time determination of meteor377 related parameters utilizing modern digital technology, $J$. Atmos. Sol. Terr. Phys., 63, 155-169, 2001.

John, S. R., K. K. Kumar, K. V. Subrahmanyam, G. Manju, and Q. Wu, Meteor radar measurements of MLT winds near the equatorial electro jet region over Thumba $(8.50 \mathrm{~N}, 770 \mathrm{E})$ : comparison with TIDI observations, Ann. Geophys., 29, 1209-1214, 2011.

Kumar, K. K., G. Ramkumar, and S. T. Shelbi, Initial results from SKiYMET meteor radar at Thumba $\left(8.5^{\circ} \mathrm{N}, 77^{\circ} \mathrm{E}\right), 1$. Comparison of wind measurements with MF spaced antenna radar system, Radio Sci., 42, RS6008, doi:10.1029/2006RS003551, 2007.

Randhawa, J. S., B. H. Williams, and M. D. Kays, Meteorological influence of a solar eclipse on the stratosphere, Technical Report ECOM$5345,1970$.

Subrahmanyam, K. V., G. Ramkumar, K. K. Kumar, D. Swain, S. V. Sunilkumar, S. S. Das, R. K. Choudhary, K. V. S. Namboodiri, K. N. Uma, S. B. Veena, S. R. John, and A. Babu, Temperature perturbation in the troposphere-stratosphere at Trivandrum during the solar eclipse 2009/2010, Ann. Geophys., 29, 275-282, 2011.

Sumod, S. G., T. K. Pant, C. Vineeth, M. M. Hossain, and M. Antonita, Response of the tropical mesopause to the longest annular solar eclipse of this millennium, J. Geophys. Res., 116, A06317, doi:10. 1029/2010JA016326, 2011.

Winkler, P., K. Uwe, K. Ulf, R. Johann, S. Hans, and A. Doris, Development of meteorological parameters and total ozone during the total solar eclipse of August11,1999, Meteorol.Z., 10(3), 193-199, 2001.

Zerefos, C. S., E. Gerasopoulos, I. Tsagouri, B. E. Psiloglou, A. Belehaki, T. Herekakis, A. Bais, S. Kazadzis, C. Eleftheratos, N. Kalivitis, and N. Mihalopoulos, Evidence of gravity waves into the atmosphere during the March 2006 total solar eclipse, Atmos. Chem. Phys., 7, 4943-4951, doi:10.5194/acp-7-4943-2007, 2007.

G. Ramkumar (e-mail: geetha_ramkumar@vssc.gov.in), K. V. Subrahmanyam, K. K. Kumar, S. S. Das, D. Swain, S. V. Sunilkumar, K. V. S. Namboodiri, K. N. Uma, V. S. Babu, S. R. John, and A. Babu 